Article

\title{
Acidocalcisome-Mitochondrion Membrane Contact Sites in Trypanosoma brucei
}

\author{
Srinivasan Ramakrishnan ${ }^{1}$, Beejan Asady ${ }^{1}$ and Roberto Docampo ${ }^{1,2, * \text { (D) }}$ \\ 1 Center for Tropical and Emerging Global Diseases, University of Georgia, Athens, GA 30602, USA; \\ sri@uga.edu (S.R.); basady@uga.edu (B.A.) \\ 2 Department of Cellular Biology, University of Georgia, Athens, GA 30602, USA \\ * Correspondence: rdocampo@uga.edu; Tel.: +1-706-542-8104
}

Received: 6 February 2018; Accepted: 14 March 2018; Published: 22 March 2018

\begin{abstract}
Membrane contact sites are regions of close apposition between two organelles, typically less than 30 nanometers apart, that facilitate transfer of biomolecules. The presence of contact sites has been demonstrated in yeast, plants, and mammalian cells. Here, we investigated the presence of such contact sites in Trypanosoma brucei. In mammalian cells, endoplasmic reticulum-mitochondria contact sites facilitate mitochondrial uptake of $\mathrm{Ca}^{2+}$ released by the ER-located inositol 1,4,5-trisphosphate receptor $\left(\mathrm{InsP}_{3} \mathrm{R}\right)$. However, the $\mathrm{InsP}_{3} \mathrm{R}$ in trypanosomes localizes to acidocalcisomes, which serve as major $\mathrm{Ca}^{2+}$ stores in these parasites. In this work, we have used super-resolution structured illumination microscopy and electron microscopy to identify membrane contact sites that exist between acidocalcisomes and mitochondria. Furthermore, we have confirmed the close association of these organelles using proximity ligation assays. Characterization of these contact sites may be a necessary starting point towards unraveling the role of $\mathrm{Ca}^{2+}$ in regulating trypanosome bioenergetics.
\end{abstract}

Keywords: membrane contact sites; calcium signaling; trypanosomes

\section{Introduction}

Trypanosoma brucei has two life cycle stages that are easily grown in the laboratory, the procyclic form (PCF), which is one of the stages present in the insect vector, and the bloodstream form (BSF), which is similar to the form present in the blood of the mammalian host. The PCF's mitochondria are well developed and possess a respiratory chain while the BSF's mitochondria are more rudimentary and do not have a functional respiratory chain nor can they perform oxidative phosphorylation; however, the mitochondria of both stages maintain a membrane potential [1-4] and are able to transport $\mathrm{Ca}^{2+}[2]$.

In vertebrate cells, the constitutive inositol 1,4,5-trisphosphate receptor $\left(\mathrm{InsP}_{3} \mathrm{R}\right)$-dependent $\mathrm{Ca}^{2+}$ transfer from the endoplasmic reticulum (ER) to the mitochondria has been found to be an essential cellular process required for efficient mitochondrial respiration and maintenance of normal cell bioenergetics [5]. This role is facilitated by the close apposition of the ER and mitochondria supported by physical linkages, or membrane contact sites (MCS). This apposition creates microdomains of high $\mathrm{Ca}^{2+}$ concentration that facilitate rapid $\mathrm{Ca}^{2+}$ transport into the mitochondria [6-9] through the mitochondrial $\mathrm{Ca}^{2+}$ uniporter (MCU) $[10,11]$.

In trypanosomatids the $\operatorname{InsP}_{3} \mathrm{R}$ is located in acidocalcisomes instead of the ER $[12,13]$. Acidocalcisomes are acidic calcium stores that appear to play a fundamental role in $\mathrm{Ca}^{2+}$ signaling in these eukaryotes [14]. Previous research has demonstrated that release of $\mathrm{Ca}^{2+}$ from acidocalcisomes causes an eight-fold increase in mitochondrial $\mathrm{Ca}^{2+}$ concentration but only a two-fold increase in the cytosolic $\mathrm{Ca}^{2+}$ concentration [15], suggesting a role of the MCU complex (MCUC) of trypanosomes in shaping the amplitude and spatiotemporal patterns of cytosolic $\mathrm{Ca}^{2+}$ increases [16]. These results also 
suggest a very close proximity between acidocalcisomes and the sole mitochondrion of T. brucei and that a similar constitutive $\mathrm{InsP}_{3} \mathrm{R}$-dependent $\mathrm{Ca}^{2+}$ release from acidocalcisomes [12] could be involved in the regulation of cell bioenergetics and cell death, as occurs between the ER and mitochondria of vertebrate cells [5].

In this work, we explored the presence of MCSs between these organelles using high-resolution microscopy, electron microscopy and the proximity ligation assay, a technique that is specialized for visualizing contact sites [17-19], and demonstrate that the membrane of acidocalcisomes indeed contact the mitochondrial outer membrane. We show that several of these described contacts occur within each cell in both PCF and BSF of T. brucei. Our findings lay the foundation for investigating acidocalcisome-mitochondrion $\mathrm{Ca}^{2+}$ transfer and will also stimulate further research in the search for contact sites between other organelles in trypanosomatid parasites.

\section{Results}

Since acidocalcisomes are the main $\mathrm{Ca}^{2+}$ storage site in trypanosomes [14] and possess an $\operatorname{InsP}_{3} \mathrm{R}$ [12], we hypothesized that they could be in close proximity to T. brucei mitochondrion, allowing rapid $\mathrm{Ca}^{2+}$ transfer across the organellar membranes. To test this hypothesis, we expressed a $T$. brucei mitochondrial outer membrane protein, the voltage-dependent anion channel (TbVDAC) [20,21], tagged with 3xHA, to label this membrane using anti-HA antibodies. Next, we used the T. brucei vacuolar $\mathrm{H}^{+}$-pyrophosphatase 1 (TbVP1) antibody to label the T. brucei acidocalcisome membrane [22]. Using super-resolution structured illumination microscopy we noticed that acidocalcisomes are often located in close vicinity to the mitochondrion. We performed such analyses in both PCF and BSF trypanosomes. In both life cycle stages, we could observe a close association between acidocalcisomes and the mitochondrion of the parasite (Figure 1). Furthermore, such contact sites could be observed in both life cycle stages wild type forms using electron microscopy as well (Figure 2). In these electron micrographs, it can be observed that in all such cases of contact, the membranes of the two organelles appear to be less than $30 \mathrm{~nm}$ apart in both PCF $(19.4 \pm 6.2 \mathrm{~nm}$ in $n=3)$ and BSF $(23.2 \pm 4.3 \mathrm{~nm}$ in $n=3)$.

To further characterize such points of contact we performed a proximity ligation assay (PLA). Fixed and permeabilized parasites were treated with primary antibodies to label the mitochondrial outer membrane and the acidocalcisomes. Then, the cells were subjected to PLA analysis. Following this method, the points of close contact between the two organelles can be observed as red fluorescent spots (Figure 3A, marked by white arrows). Acidocalcisome-mitochondrion membrane contact sites could be clearly observed in both PCF and BSF parasites. Interestingly, we found that acidocalcisome-mitochondrion membrane contact sites are more prevalent in PCF trypanosomes. Nevertheless, a substantial number of contact sites were observed in both life cycle stages (Figure 3B). A negative control using a mitochondrial inner membrane protein (mitochondrial calcium uniporter or MCU) tagged with 3xHA [23] instead of TbVDAC-3xHA, did not result in any labeling (data not shown).
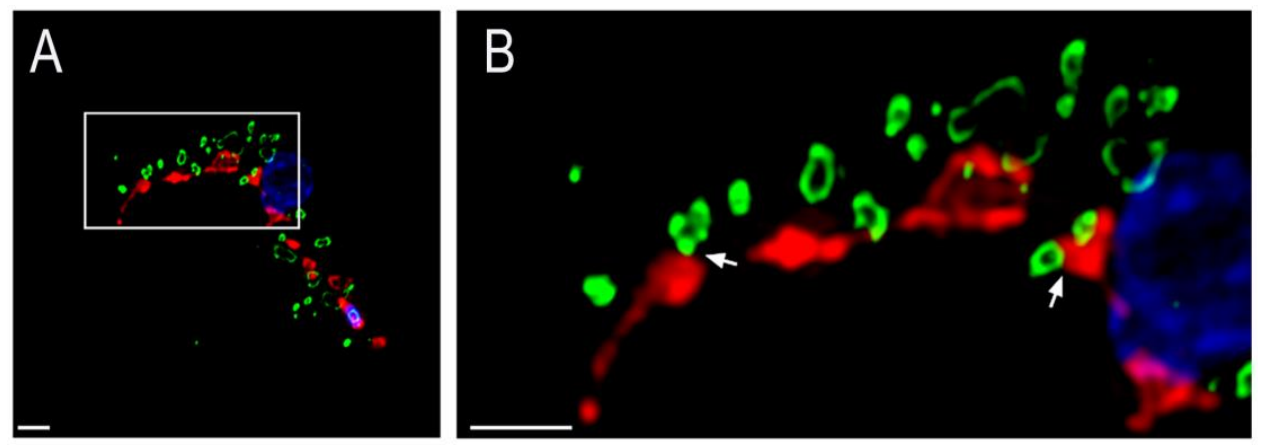

Figure 1. Cont. 

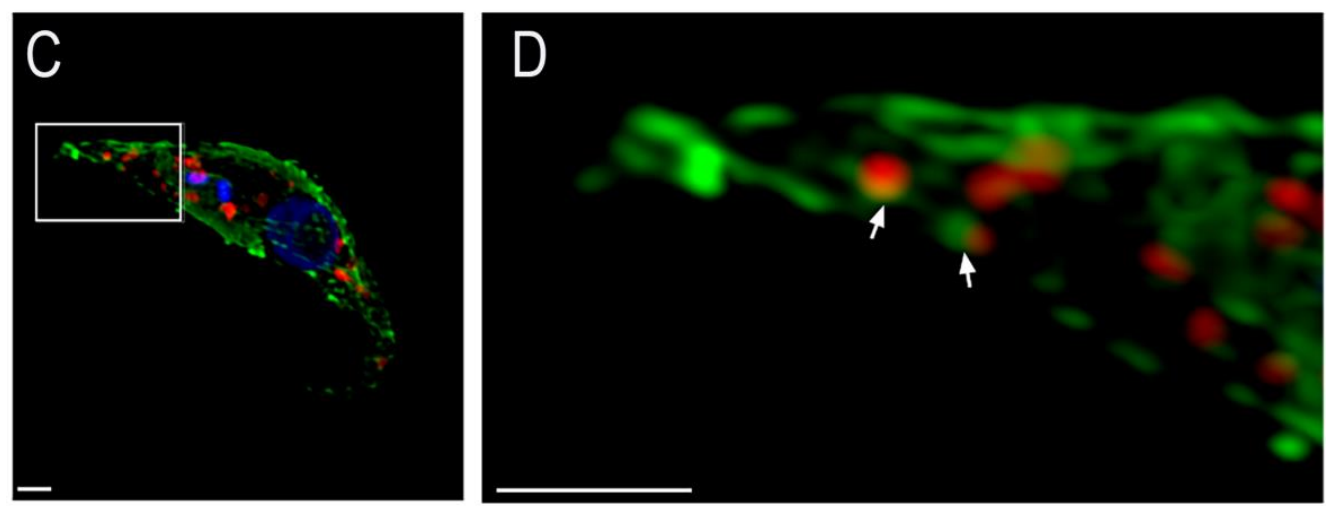

Figure 1. Representative super resolution images of T. brucei acidocalcisomes and mitochondria in BSF $(\mathbf{A}, \mathbf{B})$ and procyclic form (PCF) (C,D) trypanosomes. Close proximity between the acidocalcisomes and mitochondria could be observed in both life cycle stages and are indicated by white arrows in the magnified images (B,D). Mitochondria are in red in A/B and in green in C/D. Acidocalcisomes are in green in A/B and in red in B/C. DAPI staining of nuclei and kinetoplasts is in blue. Scale bar $=1 \mu \mathrm{m}$.
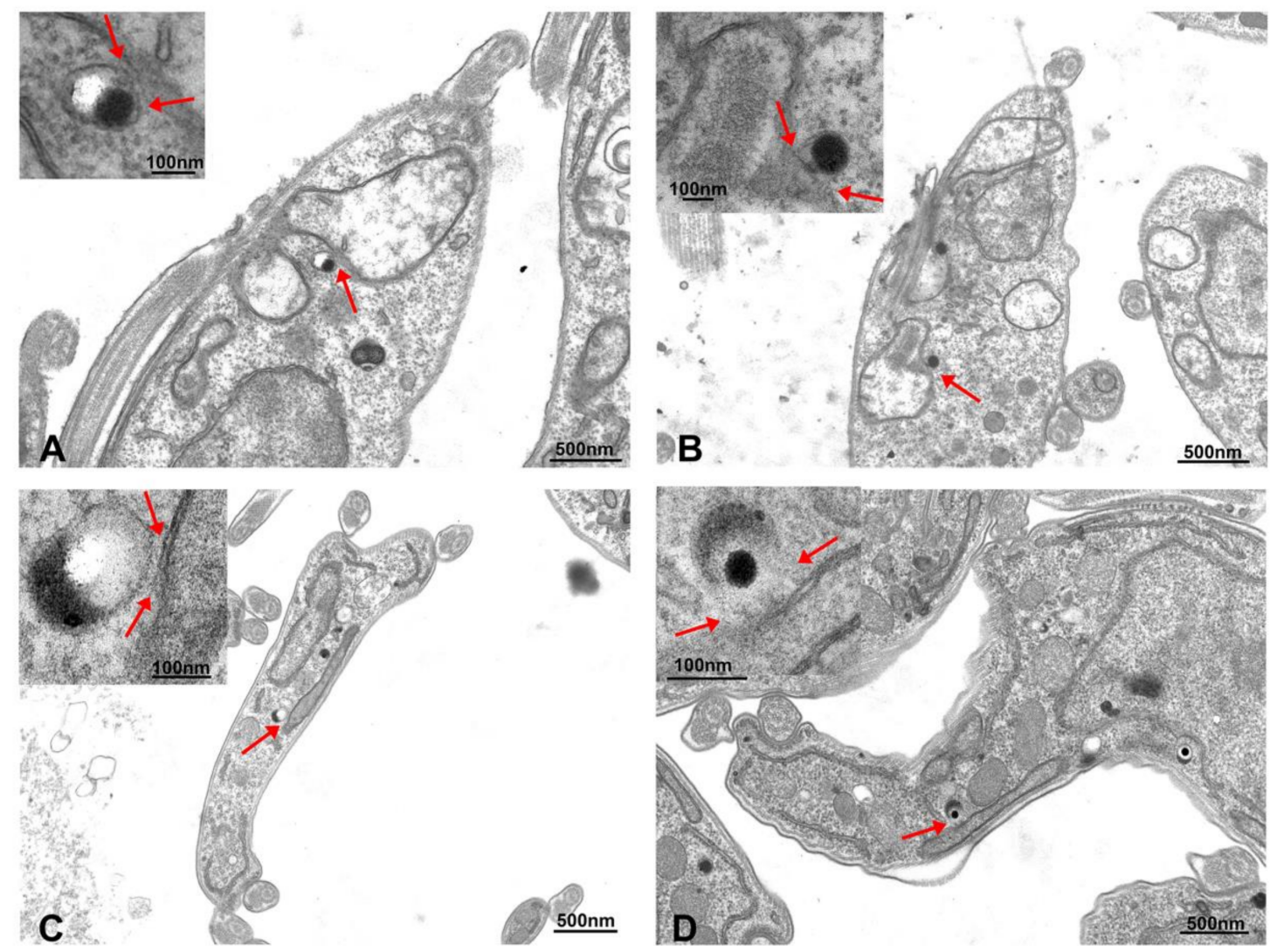

Figure 2. Representative transmission electron microscopy images of PCF (A,B) and bloodstream form (BSF) (C,D) T. brucei showing contacts between acidocalcisomes and the mitochondrion of the parasites. Acidocalcisomes appear as rounded organelles containing electron-dense material that adheres to one side of the membrane, and are seen adjacent to the mitochondrion double membrane. The contact sites could be observed in both life cycle forms and are indicated by red arrows in the insets at higher magnification. 

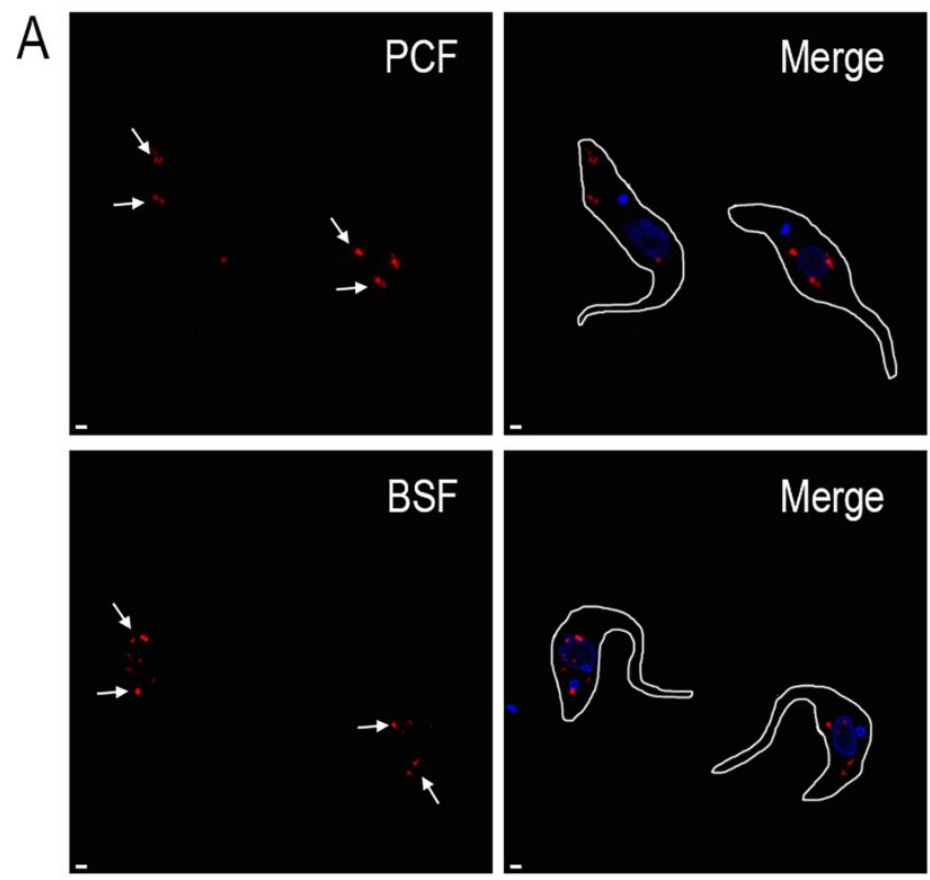

B

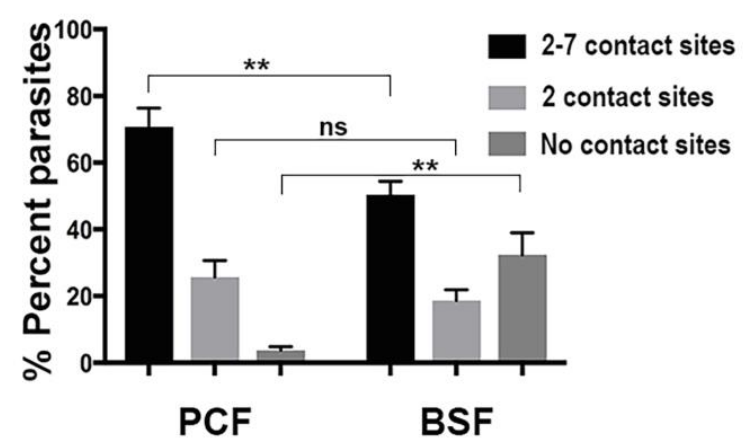

Figure 3. (A) Representative super resolution structured illumination images of T. brucei PCF and BSF trypanosomes subjected to proximity ligation assay. The red fluorescent signals indicated by the white arrows confirm the existence of membrane contact sites between acidocalcisomes and the mitochondrion in these parasites. Only some of them are labeled with arrows. DAPI staining is in blue. Merge images are at right. Scale bars $=1 \mu \mathrm{m}$; (B) Quantification of the number of contact sites observed using the proximity ligation assay. A total of one hundred PCF or one hundred BSF parasites were counted in each of three independent biological experiments $(n=3)$ and classified according to the number of contact sites observed in them. Values shown are means \pm s.d. of $n=3$. ${ }^{* *} p<0.05$, Student's $t$ test; ns is no significant difference.

\section{Discussion}

$\mathrm{Ca}^{2+}$ signaling regulates important processes in all organisms [24-26]. As a result, tight regulation of $\mathrm{Ca}^{2+}$ signaling is necessary in all cell types. This tight regulation is facilitated by the action of several $\mathrm{Ca}^{2+}$ binding proteins and transporters, which have been identified and characterized previously [27]. However, a role for MCSs in $\mathrm{Ca}^{2+}$ signaling and regulation is now emerging. In mammalian cells such MCSs are the main facilitators of $\mathrm{Ca}^{2+}$ entry into the cell [28]. Furthermore, MCSs also participate in mitochondrial $\mathrm{Ca}^{2+}$ import and thereby regulate the energy production and cell death processes within cells.

Our work is the first reporting MCSs in trypanosomes. Using immunofluorescence and super resolution structured illumination microscopy, as well as electron microscopy, we show that 
acidocalcisomes, the acidic $\mathrm{Ca}^{2+}$ stores of $T$. brucei, reside in close vicinity to the mitochondrion. To validate this observation, we used the proximity ligation assay, a tool specially designed to detect MCSs [17-19]. Using this tool we demonstrated that such MCSs are found in both PCF and BSF of T. brucei.

Overexpression of TbVDAC could have affected the extent of the contact sites. However, contact sites were also detected by electron microscopy of wild type cells.

Based on our observations we propose the model illustrated in Figure 4. The close apposition of acidocalcisomes to the mitochondrial outer membrane would create microdomains of high $\mathrm{Ca}^{2+}$ concentration generated by $\mathrm{InsP}_{3} \mathrm{R}$-driven $\mathrm{Ca}^{2+}$ release, which could be rapidly transferred to the mitochondrion through the VDAC and the MCUC. It is interesting to note that the phosphoinositide-phospholipase C (PI-PLC) of T. brucei, the enzyme responsible for $\mathrm{InsP}_{3}$ generation, is active at physiological $\mathrm{Ca}^{2+}$ concentrations, suggesting its constitutive activation [29]. Constitutive release of $\mathrm{InsP}_{3}$ would lead to acidocalcisome $\mathrm{Ca}^{2+}$ release and transfer to the mitochondrion regulating the bioenergetics of the cells, as it has been described in mammalian cells for the role of the ER-mitochondria contact sites [5].

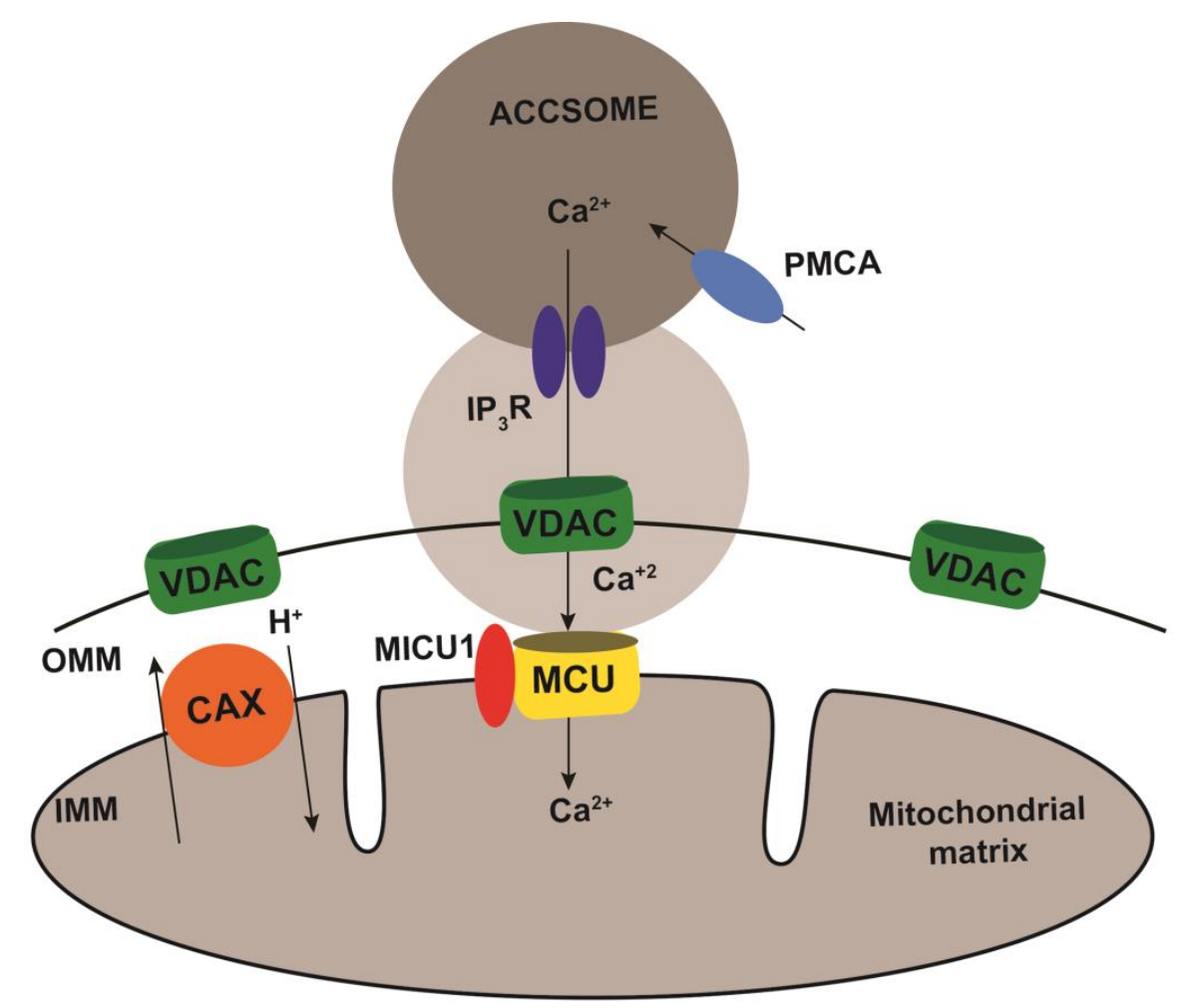

Figure 4. Model showing acidocalcisome-mitochondrion contact sites and their putative role in $\mathrm{Ca}^{2+}$ transfer in the kinetoplastid parasite T. brucei. The scheme shows the mitochondrial $\mathrm{Ca}^{2+}$ uniporter (MCU), and its gatekeeper, mitochondrial calcium uptake 1 (MICU1), and the $\mathrm{Ca}^{2+} / \mathrm{H}^{+}$exchanger mediating $\mathrm{Ca}^{2+}$ efflux across the inner mitochondrial membrane (IMM). The voltage-dependent anion channel (VDAC) is in the outer mitochondrial membrane (OMM). The acidocalcisome (Accsome) shows the inositol 1,4,5-trisphosphate receptor channel $\left(\mathrm{IP}_{3} \mathrm{R}\right)$ for $\mathrm{Ca}^{2+}$ release and plasma membrane-type $\mathrm{Ca}^{2+}$-ATPase (PMCA) for $\mathrm{Ca}^{2+}$ uptake. The grey area between the acidocalcisome and mitochondrion represents a $\mathrm{Ca}^{2+}$ microdomain.

MCSs are often held together by tethering proteins [30]. Close contacts between ER and mitochondria in yeast are maintained by the ER-mitochondria encounter structure (ERMES), which is absent in mammalian cells [31], except for the SMP domain of PDZD8 that is a functional ortholog to 
the SMP domain of yeast Mmm1 [32]. Orthologs to Mmm2 and Mdm12 have also been proposed in T. brucei [33] although they have not beed studied in detail.

In mammalian cells, ER-mitochondria MCSs are tethered by the protein GRP75 [34] and other proteins [35]. However, even if orthologs to these proteins were present in trypanosomes there is no reason to believe that they would be involved in maintaining acidocalcisome-mitochondrion MCSs. Further work is needed to investigate the specific tethers involved in this process. In mammalian cells, MCSs have been reported between multiple organelles. The ER, being the largest membrane-bound organelle, plays a main role in forming MCSs. ER-plasma membrane, ER-Golgi, ER-endosome, and ER-lipid droplet MCSs with specific functions have been described in mammalian cells [36]. Other inter-organellar MCSs such as mitochondria-vacuole [37,38], nucleus-vacuole [39], and mitochondria-lipid droplet [40] also seem to have specific intracellular roles. Indeed, it is possible that such MCSs between other organelles also exist in T. brucei. Using techniques such as proximity ligation assay and super-resolution microscopy or electron microscopy analysis, the existence of such organellar MCSs can be investigated further in T. brucei. In this regard, previous work in T. cruzi has shown that acidocalcisomes are frequently seen in close contact with other organelles and intracellular structures (mitochondria, nucleus, lipid inclusions and subpellicular microtubules) [41]. Such studies would help identify new proteins and mechanisms underlying the biology of T. brucei.

\section{Materials and Methods}

\subsection{Culture Methods}

T. brucei PCF 29-13 and BSF single marker strains (gifts from Dr. George A.M. Cross, Rockefeller University, New York) were used for all our experiments. PCF trypanosomes were grown at $27^{\circ} \mathrm{C}$ in SDM-79 medium [42], and supplemented with hemin $(7.5 \mu \mathrm{g} / \mathrm{mL})$ and $10 \%$ heat-inactivated tetracycline-free fetal bovine serum. BSF trypanosomes were grown at $37{ }^{\circ} \mathrm{C}$ in HMI-9 medium [43], supplemented with $10 \%$ tetracycline-free fetal bovine serum (FBS).

\subsection{Plasmids, Chemicals and Reagents}

The pLEW100v5-BSD vector was a gift from Dr. George A.M. Cross (Rockefeller University). TbVDAC was amplified from $T$. brucei genomic DNA using the forward primer-GTACGGATCCTTAAGCGTAATCTGGAACATCGTATGGGTAAGCGTAATCTGGAACAT CGTATGGGTAAGCGTAATCTGGAACATCGTATGGGTACGAATGGGTAATAAGGAC and reverse primer-GTACAAGCTTATGGGTCCCAGTGAGTAC and Q5 2X mastermix (Cat\# M0492S) from New England Biolabs (Ipswich, MA, USA). The amplified fragment was cloned using BamHI and HindIII restriction sites into the pLEW100v5-BSD plasmid and sequenced before transfection into the parasites. Rabbit polyclonal antibody against HA (ab9110) was purchased from Abcam (Cambridge, UK). Mouse antibodies against the vacuolar proton pyrophosphatase (TbVP1) were reported previously [22] and were provided by Dr. Norbert Bakalara (University of Montpellier, Montpellier, France). Alexa-conjugated secondary antibodies were purchased from Invitrogen (Thermo Fisher Scientific, Carlsbad, CA, USA). AMAXA human T-cell Nucleofector kit was purchased from Lonza (Basel, Switzerland). The primers were purchased from Integrated DNA Technologies (Coralville, IA, USA). Duolink Proximity ligation assay kit (DUO92101), and all other reagents of analytical grade were purchased from Sigma-Aldrich (St. Louis, MO, USA).

\subsection{Preparation of Guinea Pig Antibody against T. brucei Vacuolar Pyrophosphatase (TbVP1)}

A 357-bp fragment comprising the loop III and adjacent regions of T. brucei VP1 gene was amplified and cloned into pET23a, as previously described [22]. This construct was transformed into E. coli BL21-CodonPlus (Agilent Technologies, Santa Clara, CA, USA) for expression. Cells were lysed, and the recombinant protein was purified using HisPurNi-NTA columns under denaturing conditions, as described by the manufacturer (Thermo Fisher Scientific, Walthman, MA, USA). Antibodies were 
produced in Hartley strain Guinea pigs (Charles River Laboratories), weighing about $600 \mathrm{~g}$ each. Antigen was delivered by subdermal injections while the animal was under anesthesia with isofluorane. The primary inoculation contained $200 \mu \mathrm{g}$ purified protein mixed in equal parts with Freund's complete adjuvant. Two subsequent boosts, spaced in 3 week intervals, contained $100 \mu \mathrm{g}$ purified protein mixed in equal parts with Freund's incomplete adjuvant. Final bleeds were collected via cardiac puncture, while the animal was under deep anesthesia with isofluorane. This antibody was previously shown to localize to acidocalcisomes [44]. The study was carried out in strict accordance with the recommendations in the Guide for the Care and Use of Laboratory Animals of the United States National Institutes of Health. The animal protocol was approved by the Institutional Animal Care and Use Committee of the University of Georgia.

\subsection{Cell Transfection}

Cell transfections were done as reported previously [45]. In brief, mid-log phase PCF trypanosomes $\left(5 \times 10^{6}\right.$ cells $\left./ \mathrm{mL}\right)$ were harvested by centrifugation at $1000 \times g$ for $10 \mathrm{~min}$, washed with a Cytomix buffer ( $2 \mathrm{mM}$ EGTA, $3 \mathrm{mM} \mathrm{MgCl} 2,120 \mathrm{mM} \mathrm{KCl}, 0.5 \%$ glucose, $0.15 \mathrm{mM} \mathrm{CaCl}_{2}, 0.1 \mathrm{mg} / \mathrm{mL}$ BSA, $10 \mathrm{mM} \mathrm{K}_{2} \mathrm{HPO}_{4} / \mathrm{KH}_{2} \mathrm{PO}_{4}, 1 \mathrm{mM}$ hypoxanthine, $25 \mathrm{mM}$ Hepes, $\mathrm{pH} 7.6$ ) and resuspended in $0.4 \mathrm{~mL}$ of the same buffer at a cell density of $2.5 \times 10^{7}$ cells $/ \mathrm{mL}$. The washed cells were mixed with $50 \mu \mathrm{g}$ of plasmid DNA in a 0.4-cm electroporation cuvette and subjected to two pulses from Bio-Rad Gene Pulser Xcell (Bio-Rad, Hercules, CA, USA) electroporator set at $1.5 \mathrm{kV}$ and $25 \mu \mathrm{F}$. The stable transformants were obtained in SDM-79 medium supplemented with $15 \% \mathrm{FBS}$ and $10 \mu \mathrm{g} / \mathrm{mL}$ blasticidin. For BSF trypanosomes, $10 \mu \mathrm{g}$ of NotI-linearized plasmid DNA was used per $4 \times 10^{7}$ mid-log phase cells in $100 \mu \mathrm{L}$ AMAXA Human T-cell Nucleofector solution. Electroporation was performed using $2 \mathrm{~mm}$ gap cuvettes with program X-001 of the AMAXA Nucleofector. Following each transfection, stable transformants were selected and cloned by limiting dilution in HMI-9 medium containing $15 \%$ FBS with $5 \mu \mathrm{g} / \mathrm{mL}$ blasticidin in 24-well plates. The correct expression and regulation of epitope-tagged VDAC was confirmed by immunofluorescence and western blot analyses in absence or presence of $1 \mu \mathrm{g} / \mathrm{mL}$ tetracycline in the culture medium.

\subsection{Immunofluorescence Analyses}

PCF or BSF trypanosomes were washed with Buffer A with glucose (BAG, $116 \mathrm{mM} \mathrm{NaCl}$, $5.4 \mathrm{mM} \mathrm{KCl}, 0.8 \mathrm{mM} \mathrm{MgSO}_{4}, 50 \mathrm{mM}$ Hepes, $\mathrm{pH} 7.2$, and $5.5 \mathrm{mM}$ glucose) and then fixed with $4 \%$ paraformaldehyde at room temperature (RT) for $1 \mathrm{~h}$. The fixed parasites were washed twice with PBS for $10 \mathrm{~min}$ and then were allowed to adhere to poly-L-lysine-coated coverslips and permeabilized with 0.5\% Triton X-100/PBS for 3 min for PCF and 0.1\% Triton X-100/PBS for 5 min for BSF. After blocking with PBS containing 3\% BSA, $1 \%$ fish gelatin, $50 \mathrm{mM} \mathrm{NH}_{4} \mathrm{Cl}$ and $5 \%$ goat serum for $1 \mathrm{~h}$, trypanosomes were stained in 3\% BSA/PBS with the guinea pig antibody against TbVP1 (1:500) and anti-HA rabbit polyclonal antibody against HA (1:3500). After thoroughly washing with PBS, cells were incubated with Alexa 488 or 546-conjugated goat anti-rabbit antibody or goat anti-guinea pig at 1:1000 for $1 \mathrm{~h}$. The cells were counterstained with DAPI before mounting with Gold ProLong Gold antifade reagent (Molecular Probes) (Thermo-Scientific, Waltham, MA, USA). Fluorescent optical images were taken with a $100 \times$ oil immersion objective, a high-power solid-state $405 \mathrm{~nm}$ laser and EM-CCD camera (Andor iXon) (Andor Technology Ltd., Belfast, UK) under nonsaturating conditions in a Zeiss ELYRA S1 (SR-SIM) super resolution microscope. Images were acquired and processed with ZEN 2011 software with SIM analysis module. The ELYRA S1 system achieves a lateral resolution of $\sim 100 \mathrm{~nm}$ and an axial resolution of $\sim 200 \mathrm{~nm}$ through the use of SR-SIM.

\subsection{Transmission Electron Microscopy}

Mid-log phase PCF and BSF T. brucei were fixed overnight at RT in $2.5 \%$ glutaraldehyde in $0.1 \mathrm{M}$ cacodylate- $\mathrm{HCl}$ buffer, $\mathrm{pH}$ 7.2. The fixed parasites were rinsed in buffer and enrobed in $4 \%$ noble agar. Parasites were post-fixed for $30 \mathrm{~min}$ with $1 \% \mathrm{OsO}_{4}, 1.25 \%$ potassium ferrocyanide, and $5 \mathrm{mM}$ 
$\mathrm{CaCl}_{2}$ in $0.1 \mathrm{M}$ cacodylate buffer, $\mathrm{pH} 7.2$, dehydrated in an ascending ethanol series, and embedded in Epon resin. Ultrathin sections were stained with uranyl acetate and lead citrate. Images were acquired at $80 \mathrm{kV}$ using a JEOL JEM 1011 transmission electron microscope equipped with an XR80M Wide-Angle Multi-Discipline Mid-Mount CCD Camera from AMT (Advanced Microscopy Techniques) (AMT corp., Woburn, MA, USA).

\subsection{Proximity Ligation Assay}

Proximity ligation assay was performed according to the manufacturer's instructions. Briefly, PCF or BSF trypanosomes were washed with BAG and then fixed with $4 \%$ paraformaldehyde at $\mathrm{RT}$ for $1 \mathrm{~h}$. The fixed parasites were washed twice with PBS for $10 \mathrm{~min}$ and then were allowed to adhere to poly-L-lysine-coated coverslips and permeabilized with $0.5 \%$ Triton X-100/PBS for $3 \mathrm{~min}$ for PCF and 0.1\% Triton X-100/PBS for 5 min for BSF. After blocking with PBS containing 3\% BSA, $1 \%$ fish gelatin, $50 \mathrm{mM} \mathrm{NH}_{4} \mathrm{Cl}$ and $5 \%$ goat serum for $1 \mathrm{~h}$, trypanosomes were stained in $3 \% \mathrm{BSA} / \mathrm{PBS}$ with the mouse antibody against TbVP1 (1:500) and rabbit polyclonal antibody against HA (1:3500). A $1 \%$ bovine serum albumin solution containing the mouse and rabbit probes from the duolink kit was prepared and incubated at RT for $20 \mathrm{~min}$. After thoroughly washing the coverslips with PBS, they were incubated in the solution containing the rabbit and mouse probes for $1 \mathrm{~h}$ at $37^{\circ} \mathrm{C}$. Next, the coverslips were washed twice with buffer A provided with the kit and incubated at $37^{\circ} \mathrm{C}$ for $30 \mathrm{~min}$ with the Duolink Ligase in the Duolink ligation buffer. Next, the coverslips were washed twice with buffer A provided with the kit and then incubated at $37^{\circ} \mathrm{C}$ for $100 \mathrm{~min}$ with the Duolink polymerase in the Duolink amplification buffer. Lastly, the coverslips were washed with buffer B and mounted on Duolink in situ mounting media with DAPI. Fluorescent optical images were taken with a $100 \times$ oil immersion objective, a high-power solid-state $405 \mathrm{~nm}$ laser and EM-CCD camera (Andor iXon) under nonsaturating conditions in a Zeiss ELYRA S1 (SR-SIM) super resolution microscope. Images were acquired and processed with ZEN 2011 software with SIM analysis module.

\subsection{Statistical Analysis}

All values are expressed as means \pm s.d. and $n$ refers to the number of independent biological experiments performed. Statistical analyses were conducted using GraphPad Prism 5 (GraphPad Software, San Diego, CA, USA).

Acknowledgments: We thank George A. M. Cross and Norbert Bakalara for reagents, Melissa Storey and Melina Galizzi for the preparation of TbVP1 antibody, Mary Brown and the Georgia Electron Microscopy (GEM) facility for assistance with sample preparation and imaging, and Muthugapatti Kandasamy and the Biomedical Microscopy Core of the University of Georgia for the use of the super-resolution microscope. This work was supported by U.S. National Institutes of Health grant AI108222.

Author Contributions: S.R. and R.D. conceived and designed the experiments. B.A. prepared samples and acquired images on the E.M. S.R. performed all other experiments and analyses. S.R. and R.D. wrote the article.

Conflicts of Interest: The authors declare no conflict of interest.

\section{References}

1. Nolan, D.P.; Voorheis, H.P. The mitochondrion in bloodstream forms of Trypanosoma brucei is energized by the electrogenic pumping of protons catalysed by the $\mathrm{F}_{1} \mathrm{~F}_{0}$-ATPase. Eur. J. Biochem. 1992, 209, $207-216$. [CrossRef] [PubMed]

2. Vercesi, A.E.; Docampo, R.; Moreno, S.N. Energization-dependent $\mathrm{Ca}^{2+}$ accumulation in Trypanosoma brucei bloodstream and procyclic trypomastigotes mitochondria. Mol. Biochem. Parasitol. 1992, 56, $251-257$. [CrossRef]

3. Schnaufer, A.; Clark-Walker, G.D.; Steinberg, A.G.; Stuart, K. The F 1 -ATP synthase complex in bloodstream stage trypanosomes has an unusual and essential function. EMBO J. 2005, 24, 4029-4040. [CrossRef] [PubMed] 
4. Brown, S.V.; Hosking, P.; Li, J.; Williams, N. ATP synthase is responsible for maintaining mitochondrial membrane potential in bloodstream form Trypanosoma brucei. Eukaryot. Cell 2006, 5, 45-53. [CrossRef] [PubMed]

5. Cardenas, C.; Miller, R.A.; Smith, I.; Bui, T.; Molgo, J.; Muller, M.; Vais, H.; Cheung, K.H.; Yang, J.; Parker, I.; et al. Essential regulation of cell bioenergetics by constitutive $\mathrm{InsP}_{3}$ receptor $\mathrm{Ca}^{2+}$ transfer to mitochondria. Cell 2010, 142, 270-283. [CrossRef] [PubMed]

6. Rizzuto, R.; Brini, M.; Murgia, M.; Pozzan, T. Microdomains with high $\mathrm{Ca}^{2+}$ close to $\mathrm{IP}_{3}$-sensitive channels that are sensed by neighboring mitochondria. Science 1993, 262, 744-747. [CrossRef] [PubMed]

7. Rizzuto, R.; Pinton, P.; Carrington, W.; Fay, F.S.; Fogarty, K.E.; Lifshitz, L.M.; Tuft, R.A.; Pozzan, T. Close contacts with the endoplasmic reticulum as determinants of mitochondrial $\mathrm{Ca}^{2+}$ responses. Science 1998, 280, 1763-1766. [CrossRef] [PubMed]

8. Csordas, G.; Thomas, A.P.; Hajnoczky, G. Quasi-synaptic calcium signal transmission between endoplasmic reticulum and mitochondria. EMBO J. 1999, 18, 96-108. [CrossRef] [PubMed]

9. Csordas, G.; Varnai, P.; Golenar, T.; Roy, S.; Purkins, G.; Schneider, T.G.; Balla, T.; Hajnoczky, G. Imaging interorganelle contacts and local calcium dynamics at the ER-mitochondrial interface. Mol. Cell 2010, 39, 121-132. [CrossRef] [PubMed]

10. Baughman, J.M.; Perocchi, F.; Girgis, H.S.; Plovanich, M.; Belcher-Timme, C.A.; Sancak, Y.; Bao, X.R.; Strittmatter, L.; Goldberger, O.; Bogorad, R.L.; et al. Integrative genomics identifies MCU as an essential component of the mitochondrial calcium uniporter. Nature 2011, 476, 341-345. [CrossRef] [PubMed]

11. De Stefani, D.; Raffaello, A.; Teardo, E.; Szabo, I.; Rizzuto, R. A forty-kilodalton protein of the inner membrane is the mitochondrial calcium uniporter. Nature 2011, 476, 336-340. [CrossRef] [PubMed]

12. Huang, G.; Bartlett, P.J.; Thomas, A.P.; Moreno, S.N.; Docampo, R. Acidocalcisomes of Trypanosoma brucei have an inositol 1,4,5-trisphosphate receptor that is required for growth and infectivity. Proc. Natl. Acad. Sci. USA 2013, 110, 1887-1892. [CrossRef] [PubMed]

13. Lander, N.; Chiurillo, M.A.; Storey, M.; Vercesi, A.E.; Docampo, R. CRISPR/Cas9-mediated endogenous C-terminal tagging of Trypanosoma cruzi genes reveals the acidocalcisome localization of the inositol 1,4,5-trisphosphate receptor. J. Biol. Chem. 2016, 291, 25505-25515. [CrossRef] [PubMed]

14. Docampo, R.; Huang, G. Calcium signaling in trypanosomatid parasites. Cell Calcium 2015, 57, $194-202$. [CrossRef] [PubMed]

15. Xiong, Z.H.; Ridgley, E.L.; Enis, D.; Olness, F.; Ruben, L. Selective transfer of calcium from an acidic compartment to the mitochondrion of Trypanosoma brucei. Measurements with targeted aequorins. J. Biol. Chem. 1997, 272, 31022-31028. [CrossRef] [PubMed]

16. Docampo, R.; Lukes, J. Trypanosomes and the solution to a 50-year mitochondrial calcium mystery. Trends Parasitol. 2012, 28, 31-37. [CrossRef] [PubMed]

17. Tubbs, E.; Rieusset, J. Study of endoplasmic reticulum and mitochondria interactions by in situ proximity ligation assay in fixed cells. J. Vis. Exp. 2016, 118, e54899. [CrossRef] [PubMed]

18. Tubbs, E.; Theurey, P.; Vial, G.; Bendridi, N.; Bravard, A.; Chauvin, M.A.; Ji-Cao, J.; Zoulim, F.; Bartosch, B.; Ovize, M.; et al. Mitochondria-associated endoplasmic reticulum membrane (MAM) integrity is required for insulin signaling and is implicated in hepatic insulin resistance. Diabetes 2014, 63, 3279-3294. [CrossRef] [PubMed]

19. Gomez-Suaga, P.; Paillusson, S.; Stoica, R.; Noble, W.; Hanger, D.P.; Miller, C.C. The ER-mitochondria tethering complex VAPB-PTPIP51 regulates autophagy. Curr. Biol. 2017, 27, 371-385. [CrossRef] [PubMed]

20. Singha, U.K.; Sharma, S.; Chaudhuri, M. Downregulation of mitochondrial porin inhibits cell growth and alters respiratory phenotype in Trypanosoma brucei. Eukaryot. Cell 2009, 8, 1418-1428. [CrossRef] [PubMed]

21. Chiurillo, M.A.; Lander, N.; Bertolini, M.S.; Storey, M.; Vercesi, A.E.; Docampo, R. Different roles of mitochondrial calcium uniporter complex subunits in growth and infectivity of Trypanosoma cruzi. MBio 2017, 8, e005474-17. [CrossRef] [PubMed]

22. Lemercier, G.; Dutoya, S.; Luo, S.; Ruiz, F.A.; Rodrigues, C.O.; Baltz, T.; Docampo, R.; Bakalara, N. A vacuolar-type $\mathrm{H}^{+}$-pyrophosphatase governs maintenance of functional acidocalcisomes and growth of the insect and mammalian forms of Trypanosoma brucei. J. Biol. Chem. 2002, 277, 37369-37376. [CrossRef] [PubMed]

23. Huang, G.; Vercesi, A.E.; Docampo, R. Essential regulation of cell bioenergetics in Trypanosoma brucei by the mitochondrial calcium uniporter. Nat. Commun. 2013, 4, 2865. [CrossRef] [PubMed] 
24. Dominguez, D.C. Calcium signalling in bacteria. Mol. Microbiol. 2004, 54, 291-297. [CrossRef] [PubMed]

25. Tuteja, N.; Mahajan, S. Calcium signaling network in plants: An overview. Plant Signal. Behav. 2007, 2, 79-85. [CrossRef] [PubMed]

26. Moreno, S.N.; Docampo, R. Calcium regulation in protozoan parasites. Curr. Opin. Microbiol. 2003, 6, 359-364. [CrossRef]

27. Clapham, D.E. Calcium signaling. Cell 2007, 131, 1047-1058. [CrossRef] [PubMed]

28. Burgoyne, T.; Patel, S.; Eden, E.R. Calcium signaling at ER membrane contact sites. Biochim. Biophys. Acta 2015, 1853, 2012-2017. [CrossRef] [PubMed]

29. King-Keller, S.; Moore, C.A.; Docampo, R.; Moreno, S.N. Ca ${ }^{2+}$ Regulation of Trypanosoma brucei phosphoinositide phospholipase C. Eukaryot. Cell 2015, 14, 486-494. [CrossRef] [PubMed]

30. Eisenberg-Bord, M.; Shai, N.; Schuldiner, M.; Bohnert, M. A tether is a tether is a tether: Tethering at membrane contact sites. Dev. Cell 2016, 39, 395-409. [CrossRef] [PubMed]

31. Kornmann, B.; Currie, E.; Collins, S.R.; Schuldiner, M.; Nunnari, J.; Weissman, J.S.; Walter, P. An ER-mitochondria tethering complex revealed by a synthetic biology screen. Science 2009, 325, 477-481. [CrossRef] [PubMed]

32. Hirabayashi, Y.; Kwon, S.K.; Paek, H.; Pernice, W.M.; Paul, M.A.; Lee, J.; Erfani, P.; Raczkowski, A.; Petrey, D.S.; Pon, L.A.; et al. ER-mitochondria tethering by PDZD8 regulates $\mathrm{Ca}^{2+}$ dynamics in mammalian neurons. Science 2017, 358, 623-630. [CrossRef] [PubMed]

33. Wideman, J.G.; Gawryluk, R.M.; Gray, M.W.; Dacks, J.B. The ancient and widespread nature of the ER-mitochondria encounter structure. Mol. Biol. Evol. 2013, 30, 2044-2049. [CrossRef] [PubMed]

34. Szabadkai, G.; Bianchi, K.; Varnai, P.; De Stefani, D.; Wieckowski, M.R.; Cavagna, D.; Nagy, A.I.; Balla, T.; Rizzuto, R. Chaperone-mediated coupling of endoplasmic reticulum and mitochondrial $\mathrm{Ca}^{2+}$ channels. J. Cell Biol. 2006, 175, 901-911. [CrossRef] [PubMed]

35. Murley, A.; Nunnari, J. The emerging network of mitochondria-organelle contacts. Mol. Cell 2016, 61, 648-653. [CrossRef] [PubMed]

36. Phillips, M.J.; Voeltz, G.K. Structure and function of ER membrane contact sites with other organelles. Nat. Rev. Mol. Cell Biol. 2016, 17, 69-82. [CrossRef] [PubMed]

37. Elbaz-Alon, Y.; Rosenfeld-Gur, E.; Shinder, V.; Futerman, A.H.; Geiger, T.; Schuldiner, M. A dynamic interface between vacuoles and mitochondria in yeast. Dev. Cell 2014, 30, 95-102. [CrossRef] [PubMed]

38. Honscher, C.; Mari, M.; Auffarth, K.; Bohnert, M.; Griffith, J.; Geerts, W.; van der Laan, M.; Cabrera, M.; Reggiori, F.; Ungermann, C. Cellular metabolism regulates contact sites between vacuoles and mitochondria. Dev. Cell 2014, 30, 86-94. [CrossRef] [PubMed]

39. Kvam, E.; Goldfarb, D.S. Structure and function of nucleus-vacuole junctions: Outer-nuclear-membrane targeting of Nvj1p and a role in tryptophan uptake. J. Cell Sci. 2006, 119, 3622-3633. [CrossRef] [PubMed]

40. Wang, H.; Sreenivasan, U.; Hu, H.; Saladino, A.; Polster, B.M.; Lund, L.M.; Gong, D.W.; Stanley, W.C.; Sztalryd, C. Perilipin 5, a lipid droplet-associated protein, provides physical and metabolic linkage to mitochondria. J. Lipid Res. 2011, 52, 2159-2168. [CrossRef] [PubMed]

41. Miranda, K.; Benchimol, M.; Docampo, R.; de Souza, W. The fine structure of acidocalcisomes in Trypanosoma cruzi. Parasitol. Res. 2000, 86, 373-384. [CrossRef] [PubMed]

42. Cunningham, I. New culture medium for maintenance of tsetse tissues and growth of trypanosomatids. J. Protozool. 1977, 24, 325-329. [CrossRef] [PubMed]

43. Hirumi, H.; Hirumi, K. Continuous cultivation of Trypanosoma brucei blood stream forms in a medium containing a low concentration of serum protein without feeder cell layers. J. Parasitol. 1989, 75, 985-989. [CrossRef] [PubMed]

44. Cordeiro, C.D.; Saiardi, A.; Docampo, R. The inositol pyrophosphate synthesis pathway in Trypanosoma brucei is linked to polyphosphate synthesis in acidocalcisomes. Mol. Microbiol. 2017, 106, 319-333. [CrossRef] [PubMed]

45. Huang, G.; Ulrich, P.N.; Storey, M.; Johnson, D.; Tischer, J.; Tovar, J.A.; Moreno, S.N.; Orlando, R.; Docampo, R. Proteomic analysis of the acidocalcisome, an organelle conserved from bacteria to human cells. PLoS Pathog. 2014, 10, e1004555. [CrossRef] [PubMed] 
(C) 2018 by the authors. Licensee MDPI, Basel, Switzerland. This article is an open access article distributed under the terms and conditions of the Creative Commons Attribution (CC BY) license (http:/ / creativecommons.org/licenses/by/4.0/). 